\title{
Interacción étnica y diplomacia de fronteras en el reino miskitu \\ a fines del siglo XVIII
}

Claudia García

Universidad de Uppsala

En este trabajo me propongo examinar las interacciones sociales, étnicas y de género del reino miskitu, durante el intento de colonización española a fines del siglo XVIII. Es durante este período, y como consecuencia de acuerdos internacionales, que Gran Bretaña aceptó que su población desocupara la región, posibilitando por primera vez el asentamiento de españoles. El efimero proyecto colonizador español del reino miskitu, que se implementó desarrollando una diplomacia de fronteras con el fin de asegurar la lealtad del rey miskitu, dependió en gran medida de la historia de amor entre uno de los jefes indios principales y su cautiva española.

\section{Introducción}

El área centroamericana constituye, desde una perspectiva histórica, una zona de frontera, límite y unión de los dos grandes centros sociales y culturales indígenas precolombinos (los Andes incaicos/imperio Chibcha y Mesoamérica). A la llegada de los europeos era este territorio una zona pobre, menos significativa en centros urbanos y de organización social no tan compleja, aunque favorecida indudablemente por el contacto con aquellas dos grandes civilizaciones. La franja centroamericana del Caribe ${ }^{1}$ la poblaban tribus seminómadas de cazadores y recolectores, con una organización social igualitaria en el área geográfica que corresponde al actual territorio de Honduras y Nicaragua. Los conquistadores españoles se asentaron en la región del Pacífico del territorio centroamericano, cuyos habitantes, no obstante poseer una organización patriarcal más compleja conducida por una casta teocrática de guerreros, pudieron ser dominados con mayor facilidad.

Debido a que el área del Caribe no contaba con poblados españoles fijos, se convirtió en escenario de frecuentes interacciones entre los grupos aborígenes y los nuevos actores sociales provenientes de Europa. Los con-

1 La región del Atlántico de Nicaragua y Honduras corresponde con el área de influencia británica, y mantiene una relación socio-cultural con la región del Caribe. Para resaltar precisamente dicha relación la denomino Costa Caribe. 
quistadores españoles, que acompañados por misioneros católicos intentarían en forma periódica adentrarse en la zona (siendo rechazados violentamente la mayoría de las veces), competirían por el control de la región con los comerciantes y colonizadores británicos, los aventureros europeos, los piratas y los bucaneros. El monopolio establecido por la Corona española no limitaba la participación de los británicos en la vida económica de la colonia, ya que eran éstos quienes, por medio del contrabando, suplían a los propios colonizadores españoles de aquellos productos que les resultaba difícil obtener desde otros centros coloniales. El monopolio comercial establecido por España y el contrabando británico fueron dos aspectos complementarios de la economía del período colonial, y duraron lo que la colonización española. La articulación estructural de los litorales del Caribe y del Pacífico del actual territorio centroamericano se expresaba a diferentes niveles durante la época colonial. Desde sus respectivas bases, las poblaciones indígenas, los británicos y los españoles participarían de un juego implícito de relaciones tensas y conflictivas no exento, no obstante, de prolongados períodos pacíficos, estableciéndose en ambos casos tratados comerciales, de cooperación, acuerdos diplomáticos o intentos de acercamientos religiosos, colonizadores y sexual-afectivos.

En este trabajo me propongo discutir algunas ideas acerca de las interacciones sociales en la región del Caribe de Nicaragua y Honduras, durante el intento de colonización española del reino miskitu ${ }^{2}$ a fines del siglo XVIII. ${ }^{3}$

Profundizar en el estudio de este período histórico es importante por varios motivos. En primer lugar, porque es entonces cuando se produce la unificación de los zambos y los indios miskitu. Esta unificación, con las consecuencias político/sociales que ello implica, es el resultado indirecto de la historia de amor entre un jefe principal miskitu y su cautiva española. Además, es durante este período, y en gran medida gracias a dicha relación amorosa, cuando se crean las condiciones para la presencia oficial de

2 El nombre "miskitu" es el utilizado por el grupo para autodenominarse en la lengua indígena. En las fuentes españolas se les nombra como "mosquitos", "misquitos" o "moscos". Conociéndose el reino como "Mosquitia" y su área de influencia como "Costa de Mosquitos". En este artículo utilizaré las diferentes denominaciones, de acuerdo a las distintas fuentes, prefiriendo el término "miskitu" en mi propio análisis.

3 Debo un agradecimiento a la Fundación Wenner-Gren, Fundación en memoria de Lars Hierta y Consejo Sueco de Investigación Humanista y Social (HSFR) por las becas de postdoctorado que me concedieron y que posibilitaron la búsqueda de documentación en el Archivo General de Indias de Sevilla; así como también a la Escuela de Estudios Hispano Americanos, por la beca de alojamiento en su residencia. 
los españoles en el territorio del reino, siendo éste otro aspecto poco estudiado hasta el momento. En segundo lugar, porque gracias a que el proyecto colonizador español está bien documentado en los informes oficiales, es posible examinar diferentes aspectos de las relaciones intergrupales entre los españoles, los británicos y los miskitu.

\section{Las raíces de la discriminación étnica y de género}

Suele aceptarse que no puede hablarse de los miskitu como grupo étnico diferenciado antes del siglo XVII, ya que son el producto de la unión entre un subgrupo de indios sumu de habla dialectal bawhika, europeos y africanos. ${ }^{4}$ En diferentes fuentes se menciona que los primeros africanos llegados a la región provenían de un barco que en 1641 naufragara frente a Cabo Gracias a Dios; se sabe asimismo que estos africanos fueron hechos prisioneros por los miskitu y finalmente asimilados como miembros activos del grupo. ${ }^{5} \mathrm{El}$ aporte africano a la conformación de los miskitu continuaría durante los siglos siguientes con la llegada de esclavos liberados o escapados de diferentes lugares del Caribe. Los miskitu del área de Cabo Gracias a Dios fueron los que recibieron mayor aporte africano, lo que se refleja en el fenotipo que los caracteriza y que ha llevado a que se los denominara como "zambos" miskitu, para diferenciarlos de aquellos otros miskitu del litoral que poseen una apariencia más indígena, a quienes se llamó "indios" miskitu.

No es de extrañar que las poblaciones indígenas del área ofreciesen sus mujeres a los europeos, ya que esto sucedía de igual manera en otros contextos del continente. La primer impresión que tuvo Cristóbal Colón cuando arribó a esta Costa por primera vez en su cuarto y último viaje refleja esa "generosidad" en la entrega de mujeres. Decía el almirante:

"En Cariay, y en esas tierras de su comarca, son grandes fechiceros y muy medrosos...Cuando llegué allí luego me enviaron dos muchachas muy ataviadas, la más vieja no sería de once años y la otra de siete, ambas con tanta desenvoltura que no

4 Otro autor relaciona el origen de los miskitu con la mezcla indiscriminada entre esclavos procedentes de las Antillas y las diferentes tribus de la región (votos, ramas, ulúas, toacas, sumus, payas, etc). Sin embargo, esta versión se contradice con la mayoría de los estudios sobre el tema. Ver al respecto Beltrán y Rozpide, R.: La Mosquitia. América Central. Madrid, 1910, pág. 15.

5 Conzemius, Eduard: "Ethnographical Survey of the Miskitu and Sumu Indians of Honduras and Nicaragua.” Smithsonian Institution. Bureau of American Ethnology. Washington, 1932, pág. 17. 
serían más que unas putas...en llegando las mandé adornar de nuestras cosas y las envié luego a tierra...”

La actitud de manifiesto rechazo de Colón ante esta bienvenida ofrecida por las dos muchachas, enviadas por los suyos a recibir a los extranjeros, no sería el patrón común de comportamiento de los europeos en América. Los conquistadores españoles eran hombres solos, pese a que la política pobladora de la Corona había llevado a incluir mujeres como pasajeras ya en el segundo viaje de Colón. Posteriormente, se regularían los viajes a las Indias disponiéndose que no podrían viajar aquellos hombres que dejasen a sus esposas en España. Sin embargo, se concedía un período de dos años para que los viajeros regresasen a buscar a sus familias, lo que si bien no muchas veces se respetaba era indicio de que existía una clara política poblacional para los territorios recién descubiertos. Esta era inexistente en el caso de Gran Bretaña, siendo la población de este origen que llegaba a la costa del Caribe centroamericano exclusivamente masculina. Ambos, españoles y británicos, entablaron relaciones sexual-afectivas con las mujeres nativas, pero éstas adquirieron características diferenciadas ya fuese que se tratase de las áreas del Pacífico (predominio español) o del Caribe (bajo influencia británica). Si bien no ha sido éste uno de los temas más populares, se ha comenzado a considerar las consecuencias de la conquista para las mujeres indígenas, especialmente en lo que se refiere a hallar una explicación satisfactoria del mestizaje. No existe, sin embargo, ningún estudio que profundice en el carácter de las relaciones entre hombres y mujeres en el sector del Caribe de Nicaragua y Honduras. Se sabe que a poco de iniciarse el siglo XVII existía una colonia de puritanos en la isla de Providencia, y que desde allí se implementaba el comercio con las poblaciones indígenas del Cabo Gracias a Dios. Se ha señalado también que todos los puritanos tenían varias mujeres indígenas, pese a las claras directivas de que no debían mezclarse con ellas. La cuestión pareciera haber alcanzado una dimensión problemática, ya que la dirección de la compañía de los puritanos discutió esta situación y la regularizó haciéndola aceptable, por medio del compromiso de que los hijos engendrados con las mujeres indígenas serían bautizados y educados en forma cristiana. ${ }^{7}$

6 Carta de Colón a los Reyes de España, informándoles de su cuarto y último viaje, escrita en la isla de Jamaica el 7 de Julio de 1503, citada en Documentos para la historia de Nicaragua. Madrid, 1954, vol. I, págs. 9-10.

7 Sorsby, William: "Una compañía puritana en la Mosquitia." Nicaraguac. Managua, octubre 1982, pág. 70. 
Esta costumbre de bautizar a los hijos tenidos con las mujeres miskitu se convertiría en una práctica común. Se menciona, por ejemplo, que los capitanes de los barcos que llegaban de Jamaica solían realizar esa ceremonia anualmente con todos los niños nacidos en su ausencia, y se afirma que:

"many of them are indebted of these men more than baptism. In proof of this, I could enumerate more than a dozen acknowledged children of two of these captains".

Las tempranas relaciones comerciales entabladas por los británicos crearon las condiciones para transformar el modelo indígena de relaciones de género y contribuyeron a implementar la segregación étnica en la región. Ambos modelos se institucionalizaron al establecerse un reino con una dinastía miskitu, reconocida y apoyada por Gran Bretaña en 1687.

Un pirata que recorrió la región en la segunda mitad del siglo XVII ofrece uno de los primeros testimonios acerca del rol que ocupaban las mujeres miskitu en el juego de transacciones comerciales entre los indígenas y los europeos. Al parecer, las mujeres se amancebaban con los hombre no miskitu que llegaban a la región y mantenían con ellos un trato equivalente al que tenían con los hombres de su propio grupo. Se intercambiaban de esta manera los servicios domésticos y sexuales de las mujeres por algún producto que el sector masculino apreciaba, debido a su calidad de no tradicional. La mujer quedaba comprometida a permanecer con ese hombre no miskitu durante su estadía y, cuando éste se ausentaba, volvía a reintegrarse a la vida tradicional de la comunidad, donde era aceptada sin reservas tanto ella como los hijos que esas relaciones produjeran. ${ }^{9}$

Los hombres miskitu conformaron el brazo armado de los británicos en el área centroamericana y, en calidad de tal, solían acompañarlos en sus viajes. Un viajero del siglo XVIII menciona que las ausencias masculinas se prolongaban a veces por varios años y que estaba socialmente aceptado que la mujer conviviese con otro hombre durante el tiempo que su compañero fijo estuviese alejado. ${ }^{10}$

Entre los miskitu las relaciones sexual-afectivas eran expresivas y desinhibidas, especialmente en el contexto de las fiestas, caracterizadas por

8 Roberts, O. W.: Narrative of Voyagues and Excursions on the East Coast in the Interior of Central America. Edinburgh, (1818) 1927, pág. 35.

9 Exquemelin, Alexander: "Piratas de América." Nicaraguac. Managua, (1684) octubre 1982, pág. 34.

10 M.W.: The Mosquito Indian and his Golden River. A Collection of Voyages and Travels. London, 1732, vol. 6, pág. 115. 
un gran consumo de mishla y ebriedad ritual. Un pirata francés invitado a participar en una de estas fiestas observa que:

“...después...comienzan a beber del licor que antes he mencionado...luego vienen muchas canciones y caricias a las hembras. Y llega esto hasta el punto de que para demostrarles los hombres su inmenso amor toman una azagaya y se clavan la punta en su miembro viril, cosa que yo me negaba a creer hasta que vi con mis propios ojos esa y otras semejantes. Y no lo hacen únicamente en tales ocasiones, sino también en cualquier momento en que declaran su amor a la mujer deseada."

Los miskitu practicaban la poligamia y se aceptaba que un hombre tuviese tantas esposas como pudiera mantener. Cabe preguntarse de qué forma se equilibraron las prácticas de la poligamia con el intercambio temporal de mujeres miskitu con los europeos. Quiero sugerir la posibilidad de considerar las guerras interétnicas, que se sucedieron en forma continua durante los siglos XVII a XVIII, como el factor que equilibró este intercambio. Las relaciones sexual-afectivas intergrupales de los hombres se dieron con otras mujeres indígenas de las tribus conquistadas o con mujeres de diversos orígenes étnicos de los poblados españoles que fueron atacados, tratándose en la mayoría de los casos de mujeres que se asimilarían forzosa o voluntariamente al grupo.

Estas guerras intergrupales en la región fueron resultado de la obtención de armas de fuego por parte de los miskitu, y dieron origen a un paulatino proceso de segregación étnica. Dichas armas fueron conseguidas por medio del intercambio con los británicos, quienes les pagaban con productos no tradicionales aquellos otros locales que eran de su interés, incluyendo dentro de esta categoría a las mujeres indígenas. El poderío militar del grupo y su supremacía local en desmedro de las otras tribus indígenas se basó, precisamente, en la adquisición de esas armas de fuego que periodizaron las luchas interétnicas y las convirtieron en una empresa económica organizada a fin de obtener prisioneros que se pudiesen vender como esclavos, ya fuese para el trabajo en el área o para su exportación a otros centros coloniales.

Las quejas de las autoridades españolas se repitieron y se volvieron asiduas. El gobernador de Costa Rica se pronunciaba, por ejemplo, acerca de las hostilidades de los miskitu en el Valle de Matina, asegurando que de allí se habían llevado:

11 Exquemelin: "Piratas...", págs. 35-36. Cabe señalar que la laceración sexual del pene era una práctica precolombina usual y demostraba un gran sacrificio personal. 
"las cosechas de cacao, los esclavos que los vecinos tienen al cultivo de las haciendas y muchas personas libres de color, vendiéndolas por esclavos en las colonias de Jamayca, Curazao y en otras poblaciones que tienen en esta comarca." ${ }^{12}$

De esta forma se generaron las condiciones para el establecimiento de una sociedad étnicamente segregada. Los hombres de las tribus que habitaban el actual territorio centroamericano, hacia los cuales los miskitu dirigían sus ataques, era hechos prisioneros y vendidos como esclavos a los europeos, mientras que sus mujeres eran adoptadas como "esclavas" para todo servicio, inclusive el sexual, siendo de esta forma asimiladas culturalmente con el correr del tiempo. ${ }^{13}$ La Gazeta mensual de Guatemala del 9 de abril de 1730 se refería a esta situación en los siguientes términos:

"(los miskitu no) tienen más riqueza que la que adquieren del robo, y algún comercio que tienen de los frutos que lleva su país con los ingleses, de quienes adquieren armas de fuego, con que infestan nuestras costas, y saquean nuestros pueblos, llevándose la gente, de la cual los hombres venden por esclavos a los ingleses, y las mugeres, que es su más apreciable robo, aplican a su torpe uso, asiéndolas a todos comunes."14

Es así como la alianza militar miskitu-británica tuvo como resultado la captura de un número incierto de mujeres españolas, negras, mulatas o indígenas de los poblados del Pacífico, que corrieron la misma suerte que sus semejantes de la región del Caribe centroamericano. En un informe del ingeniero Díaz Navarro, dirigido al Marqués de Pozoblanco, se decía que:

"Las mujeres que tienen, así esta nación (la Mosquitia) como los zambos e ingleses y demás, las han robado de nuestras poblaciones inmediatas: por el año pasado de 1743 sacaron del pueblo de Jinotega, en el partido de Matagalpa, cuarenta mujeres y niños, cuya entrada hicieron cien indios mosquitos y zambos y cuatro o cinco ingleses..." ${ }^{15}$

El aumento poblacional de los miskitu, pujante y constante hasta convertirlo en el grupo predominante del área, puede relacionarse con el rol de esas mujeres miskitu, condicionadas a servir sexualmente a hombres no miskitu, y con el de esas otras mujeres no miskitu en un inicio, pero "amiskitadas" con el transcurso del tiempo, como consecuencia de ser obligadas a convivir con los hombres miskitu.

12 García Peláez, Francisco de Paula: Memorias para el antiguo reino de Guatemala. Guatemala, (1851) 1943, vol. II, pág. 121.

13 M.W.: The Mosquito Indian... pág. 122.

14 La Gazeta de Goatemala, del 19 de abril de 1730, citada en García Peláez: Memorias...,

15 Ayón, T.: Historia de Nicaragua. Madrid, 1956, pág. 347. 
Para las autoridades españolas constituían los ataques miskitu un problema de grandes dimensiones. El gobernador de la provincia de Nicaragua, José Antonio Lacayo de Briones, escribía en 1759:

\footnotetext{
"No puedo referir sin dolor las hostilidades e invasiones que ha experimentado esta provincia en este siglo, por los indios zambos mosquitos, por sí en tiempos de paz, y tripulados con ingleses en el de guerra, por el año 1709 y 1710, saquearon por tres veces el partido de Chontales, robando y talando sus haciendas, y llevándose diferentes familias prisioneras." 16
}

Puede decirse, en suma, que el modelo de género originado durante el período colonial se caracterizó por una clara tendencia hacia las uniones sexual-afectivas exógamas tanto del sector femenino como del masculino. La exogamia, sin embargo, no debilitó los límites étnicos sino que contribuyó al aumento numérico del grupo y a su consolidación como grupo predominante del área. Esto se debió a que la mayor parte de las relaciones sexual-afectivas intergrupales protagonizadas por las mujeres miskitu fueron temporales, retornando éstas con sus hijos al seno de la comunidad, donde la nueva generación fue socializada en forma tradicional. Asimismo, influyó el hecho de que los hombres miskitu incorporaran a mujeres de distinta procedencia étnica al grupo, asimilándolas a la cultura predominante.

\section{La colonización española del reino miskitu.}

Los piratas y bucaneros británicos tenían su centro de operaciones en la región del Caribe de Centroamérica, en las islas de Jamaica y Tortuga, y desde allí en forma periódica dirigían sus ataques contra los asentamientos españoles localizados en la región del Pacífico, interceptando también el tráfico de productos a España. El éxito de estos ataques residía en la cooperación brindada por los indios miskitu, integrados al área de influencia británica por el apoyo que esta potencia brindara a la creación del reino (1687) y ratificara al establecer la superintendencia en 1749. No obstante ser la presencia española en la región inexistente, la Corona se negaba a admitir que estos territorios estuviesen fuera de su jurisdicción. En la segunda mitad del siglo XVIII se negoció que Gran Bretaña abandonaría la

16 García Peláez: Memorias..., pág. 121. 
zona y se le concedió a cambio la región de Belice. ${ }^{17}$ La evacuación de la población inglesa se produjo un año después, en 1787, momento a partir del cual la Corona española se propondría colonizar el área. ${ }^{18}$ Este proyecto, no obstante, no sería exitoso y no se prolongó por más de trece años de constantes e infructuosos intentos por conocer el área y sus habitantes. Tal como acertadamente se ha afirmado, la Costa de Mosquitos fue el último enclave colonial establecido por España en el período previo a la independencia y el primero que tuvo que abandonar. ${ }^{19}$

Tratando de tener presencia en la región, España planeó la fundación de establecimientos en cuatro poblados (Río Tinto, Cabo de Gracias a Dios, Bluefields y Río San Juan), desde donde debería implementarse el acercamiento por medios pacíficos a la población local. Río Tinto (Black River) había sido fundado por los comerciantes ingleses y convertido en sede de la superintendencia en 1749. Los españoles se posesionaron de este poblado, lo nombraron en español, e intentaron desde allí colonizar el área mediante la migración de familias provenientes de Asturias, Galicia y Canarias. ${ }^{20}$

Bluefields fue el lugar considerado más adecuado para un establecimiento español, ${ }^{21}$ que, no obstante, no llegó a concretarse debido a que resultaba innecesario asumir ese gasto porque se contaba allí con un hombre de confianza, el coronel Roberto Hodgson. Este había pactado no ser afectado por la evacuación a cambio de colaborar con las autoridades españolas. ${ }^{22}$ Los otros dos lugares propuestos, Cabo de Gracias a Dios y

17 Este acuerdo se denominó "la Convención Mosquita" y fue firmado en Londres en 1786. Por él, Gran Bretaña se comprometía a evacuar el área del Caribe centroamericano que correspondía al actual territorio de Nicaragua y Honduras, zona de influencia del reino miskitu en aquellos momentos.

18 La población inglesa evacuada la componían 569 colonos ingleses y 1.763 esclavos negros, quienes fueron trasladados llevando todas sus pertenencias, inclusive 204 cabezas de ganado. Gámez, José Dolores: Historia de la Costa de Mosquitos. Madrid, 1939, pág. 143. Algunos ingleses pactaron con las autoridades españolas para permanecer en la región y muchos de sus esclavos también se quedaron, consolidando el grupo creole.

19 Sorsby, William. "Spanish Colonization on the Mosquito Coast, 1787-1800". Revista de Historia de América, 73/74, México, 1972, pág.152.

20 AGS, Secretaría de Guerra, 6948, exp. 2: Repoblación Costa de Mosquitos, 1788. AGI, Secretaría de Guerra, 6948, exp. 13: Población Costa de Mosquitos, 1787.

21 Una de las propuestas sobre la fundación de Bluefields la realizó el capitán Miguel Sanchez-Pareja, encontrándose esta documentación en AGS, Secretaría de Guerra, 6951, exp. 3: Atracción de Indios Moscos, 1791-1799. Los informes acerca de los gastos que ocasionaban los establecimientos en la región se agrupan, entre otros, en AGS, Secretaría de Guerra, 6949, exp. 14: Costo anual de establecimientos en Mosquitos, 1790.

22 Roberto Hodgson padre había sido enviado por el gobernador de Jamaica a la Costa con la misión de consolidar la amistad entre los miskitu y Gran Bretaña. Debido a lo exitoso de su misión se le nombró superintendente en 1749. Hodgson fue el primero de una serie de superintendentes ingleses que supervisaría la política del reino hasta la evacuación de la población británica en 1786. 
Río San Juan, no pasaron de ser provisorios poblados de efímera existencia. Muy pocos fueron los colonos españoles que sobrevivieron a las epidemias, y que aún vivían en la región después de 1790. Estos aseguraban sentirse en permanente inseguridad debido a la posibilidad de ser atacados tanto por los británicos como por los miskitu. ${ }^{23}$

La política española para el reino no fue más que un intento por suplir la presencia británica con una diplomacia de fronteras, en donde no se escatimarían esfuerzos por evitar los ataques miskitu. Esta política estaba acorde tanto con la Real Orden del 18 de junio de 1791, que regulaba la entrega periódica de regalos a los miskitu, ${ }^{24}$ como con lo estipulado en el artículo 14 de la Convención Mosquita, donde se acordaba que:

"Su Majestad católica, escuchando sólo los sentimientos de su humanidad promete al rey de Inglaterra que no usará de severidad con los indios mosquitos, que habitan parte de los países que deberán ser evacuados en virtud de esta convención, por causa de las relaciones que haya habido entre dichos indios y los ingleses; y su majestad británica ofrece por su parte que prohibirá rigurosamente a todos sus vasallos que suministren armas o municiones de guerra a los indios en general, situados en las fronteras de las posesiones españolas." ${ }^{25}$

Los diferentes informes que las autoridades locales presentaban a las de Guatemala coincidían al evaluar que la mejor forma de relacionarse con los miskitu era favorecerlos con un trato similar al que habían recibido de parte de los británicos. Es así como se afirmaba que:

"el medio preferible, o único para tenerlos contentos es el de los cambios, a imitación de los ingleses, admitiéndoles todo lo que produce aquel terreno y surtiéndoles de quanto ellos necesitan, a saver: de anzuelos, aparejos de pescar, achas, machetes, algunas escopetas y municiones para cazar, aguardiente, crudos angostos, listados ordinarios y otras diferentes ropas bastas que ellos usan."26

Se insistía en que los productos debían ser de buena calidad, porque los miskitu rechazaban o menospreciaban aquellos que los españoles les hacían llegar desde la Habana y Cartagena. Se repetía que los miskitu esta-

23 Sobre la colonización española en la Costa de Mosquitos puede consultarse: Sorsby, "Spanish Colonization...", pág. 150..

24 AGS, Secretaría de Guerra, 6951, exp. 3...

25 Sánchez Pedrote, Enrique: "El coronel Hodgson y la expedición a la Costa de Mosquitos", Anuario de Estudios Americanos, separata del tomo XXIII, 1958, pág. 7.

26 "Varias noticias del río San Juan, Yslas adyacentes de la Costa de los Mosquitos, provincias y partidos que tiene el reyno de Goatemala, años 1791 a 1804, “ en Relaciones ... Madrid, 1908, pág. 299. 
ban acostumbrados a la calidad de los productos europeos que habían recibido de los británicos, y que los que entregaban los españoles no los habían apreciado ni usado por ser "toscos y pesados." ${ }^{27}$

Cuando los británicos despoblaron la región, el reino estaba dividido en dos parcialidades, la de los zambos que acataban la autoridad del rey George $^{28}$ y la de los indios, bajo el mandato del gobernador Briton. Esta estructura de autoridad se veía reforzada por un almirante, un general, un coronel y jefes menores. La relación entre Briton y George era, al parecer, amistosa ya que ambos colaboraban en asuntos de guerra y comercio. Se evaluaba la población de los zambos en 6.000, de los cuales la mayoría eran hombres armados, y la de los indios en aproximadamente la mitad, señalándose que estos últimos contaban con 600 "soldados aguerridos." ${ }^{29}$ Uno de los primeros informes realizados por los españoles, luego de un viaje de reconocimiento, comunicaba que la parcialidad de George era la más respetable, especialmente por "sus mayores conocimientos nacidos por el roce que él y sus súbditos...han tenido con los extrangeros." ${ }^{{ }^{30}} \mathrm{El}$ área poblada por ambos, zambos e indios miskitu, se extendía desde el Río Tinto al Río Mico, y en toda esta zona se reconocía la autoridad de George como superior; sin embargo, las intrigas y desentendimientos entre zambos e indios no estaban ausentes de la vida del reino.

No había poblados grandes, sino pequeños caseríos dispersos, siendo el asentamiento medio de unas diez o veinte casas. Aún a fines del siglo XVIII los miskitu, pese a la existencia de aldeas más o menos permanentes, continuaban trasladándose en forma ocasional, especialmente en las épocas de caza y pesca. Por su parte ambos jefes, el rey y el gobernador, tenían más de una residencia entre las que alternaban. El rey George, por ejemplo, residía gran parte del año en Sandy Bay y, periódicamente, en Dancin, Río Coco arriba, siempre dentro de su área de dominio circunscrita a Cabo Gracias a Dios. Un ingeniero español, a quien en 1790 se le encomendó el reconocimiento de la región, manifestaba que todos los zambos

27 "Relación del reconocimiento geométrico y político de la Costa de Mosquitos, desde el establecimiento del Cabo de Gracias a Dios hasta el de Blewfields, practicado por el ingeniero ordinario Don Antonio Porta Costas, en virtud de orden del M.I.S. Presidente don José de Estachería. Año 1790 “, en Relaciones ...pág. 283.

28 El rey George fue el quinto rey miskitu desde la instauración del reino. Se lo conoce como "George I" y gobernó durante el período 1755-1766, momento en el que se concretó la unidad del reino.

29 Gámez: Historia..., pág. 143.

30 "Varias noticias del río San Juan...”, pág. 164. 
del distrito que se extendía desde Cabo Gracias hasta Sandy Bay, así como los de la laguna de Perlas, eran partidarios del rey George. ${ }^{31}$

La imagen del rey George, que por ese entonces tenía aproximadamente unos treinta años, era la de un hombre agradable, de "aspecto formidable" y "grave". ${ }^{32}$ Cuando se hacía presente en algún lugar lo acompañaba siempre una comitiva de treinta o cuarenta miskitu, entre los que se contaban sus jefes principales. Era costumbre recibirlo con honores en las naves inglesas y despedirlo con salvas de cañonazos. De él se ha dicho:

“...con su sola presencia infunde respeto en sus súbditos, que le tratan con quanta sumisión cabe en su barbarie, sin atreverse a estar tocados ni sentados delante de él..." ${ }^{3}$

Su autoridad se acentúa al subrayarse sus rasgos despóticos:

"goza sobre todos sus dependientes y partidarios una autoridad y jurisdicción enteramente despótica, ni hay más ley que su gusto, ni a su gusto oposición.” ${ }^{34}$

\section{Además:}

"de nada experimenta falta, porque es con propiedad dueño de vidas y haciendas, de que resulta si alguna cosa necesita, la toma del primero que la tiene, sin que éste tenga derecho a negársela." ${ }^{35}$

Sin embargo, el autor de esta descripción entra en contradicciones consigo mismo al afirmar que:

"de la misma manera que es dueño absoluto de los bienes de sus dependientes, lo son éstos de los suyos, porque tienen derecho a todo lo que sobra del gasto de su casa." ${ }^{36}$

Esta última versión pareciera acercarse más a la realidad, y concordar con otras acerca del valor de la propiedad entre los miskitu. Se sabe, por ejemplo, que el rey repartía los regalos que recibía entre sus partidarios, aunque primero seleccionase una parte para su propia familia. ${ }^{37}$

31 “Relación del reconocimiento...”, pág. 264.

32 Ibídem.

33 Ibídem.

34 Ibídem.

35 Ibídem.

36 Ibídem.

37 AGS, Secretaría de Guerra, 6946, exp. 18: Informe de Félix Jons sobre Mosquitos, 1787. 
A catorce leguas de Sandy Bay, se localizaba la residencia del gobernador Briton en Tubapi, asentamiento de 26 casas. La autoridad de Briton era también significativa e impresionaría a dos capitanes españoles que lo visitaron, quienes relataron que cuando bajaron a tierra la gente del gobernador estaba formada en dos filas que se extendían desde la playa hasta su casa. Algunos de los partidarios del gobernador tenían "alabardas...una bandera ynglesa en un asta, y en otra un gallardete francés en señal de paz", y de esta forma y "a caja batiente" fueron conducidos por el intérprete a la casa donde se alojarían, a la espera de que el gobernador los recibiese. ${ }^{38}$

El gobernador de la provincia de Nicaragua, Juan de Ayssa, luego de entrevistarse con el gobernador Briton en 1787, lo describía en los siguientes términos:

"Es de edad de más de 50 años, de aire despejado, buena estatura, semblante agradable y se maneja con libertad sin que le embaracen el vestido, el bastón y espada. Come con aseo, es muy parco y apenas prueba licor..." ${ }^{39}$

La vida económica del reino se había ido estructurando desde el siglo XVII en torno al intercambio con los británicos. Esto implicaba una actividad económica rudimentaria de recolección de zarzaparrilla, carey, plumas, pieles, la caza de la tortuga, el corte de madera, etc., y en especial, los ataques a los poblados españoles donde se obtenían dos bienes preciados: ganado, con el que enriquecer la dieta, y prisioneros. Los prisioneros masculinos eran o bien vendidos a los británicos para obtener otros productos (en especial armas de fuego), o bien se les obligaba a trabajar en las plantaciones de los miskitu para así aumentar la capacidad de intercambio. En el caso de las mujeres, como ya se ha dicho, éstas eran repartidas o vendidas a los hombres miskitu o a los británicos, siendo obligadas a convertirse en las "esclavas" de estos hombres para todo trabajo doméstico, además del servicio sexual y la procreación de hijos.

Esta estructura económica del reino tenía su foco principal en Bluefields, siendo éste el centro de actividades de un personaje controvertido: el coronel Roberto Hodgson, hijo de aquel otro Roberto Hodgson nombrado superintendente de la Costa en 1749. Estaba casado con Isabel Pytt, hija de un comerciante británico (Samuel Pytt) y de una española que naufragara en la Costa y que fuera recuperada por éste de manos de los indios para

38 Ibídem.

39 Carta de Ayssa, citada en Gámez: Historia..., pág. 154. 
hacerla su esposa. Así como Samuel Pytt había sido un personaje socialmente importante y respetado en la región, el coronel Roberto Hodgson despertaba sentimientos encontrados. La mayor parte del comercio local se concentraba en sus manos. Disponía de un bergantín, una balandra y una fragata con las que transportaba los productos locales a Jamaica, las colonias de Norteamérica y Gran Bretaña, abasteciendo el reino de productos manufacturados europeos. En su establecimiento contaba con la ayuda de otros europeos de diferentes nacionalidades y de, por lo menos, doscientos esclavos negros. No sólo se dedicaba a la explotación maderera, sino que intercambiaba con las poblaciones nativas los productos que traía de Jamaica por otros locales. Este intercambio era considerado por muchos desigual y en ciertos informes se mencionaban las quejas de los miskitu por el "despotismo" y el "maltrato" que recibían de Hodgson. ${ }^{40}$ En un área poco poblada como era la Costa del Caribe de Nicaragua y Honduras, luego de la evacuación de la población británica, Hodgson era indudablemente el representante por excelencia del poder económico. No es de extrañar que las autoridades españolas trataran de pactar con él y de lograr su apoyo para ganarse la simpatía de los miskitu. ${ }^{41}$

A partir del alejamiento de la población británica, los españoles habían comenzado a recorrer la región con fines claros y precisos: por un lado, realizar un reconocimiento del área, evaluando la capacidad de guerra de los miskitu; por otro, intentar negociar la devolución de los prisioneros de guerra. Los barcos comisionados para colaborar y supervisar el traslado de los británicos llevaban como directivas entregar regalos a los miskitu y negociar la devolución de los prisioneros. El capitán de fragata y comandante de la Corbeta San Pío, Gonzalo Vallejo, acompañado de Marcos Jonter, invitó con este motivo al rey George a comer en el navío para agasajarlo e iniciar los tratos. Este se disculpó aduciendo motivos de salud, pero envió en su lugar al general Roberto, su suegro, acompañado de una comitiva. Según el relato del propio Vallejo, "fueron obsequiados del mejor modo posible." ${ }^{42}$ Se les hizo entrega de algunos comestibles y se les reiteró la invitación para el día siguiente. En esa segunda ocasión, el general Roberto manifestó que su presencia se debía sólo a que había venido a

40 AGS, Secretaría de Guerra, 6946, exp. 18....

41 Sánchez Pedrote: "El coronel....", págs. 9-10.

42 "Diario de ocurrencias particulares acaecidas en las dos ocasiones que el Capitan de Fragata y Comandante de la Corbeta San Pío, Don Gonzalo Vallejo, se le comisionó en la Costa de Mosquitos desde el Río Tinto a los establecimientos de Barlovento”, en Relaciones históricas..., pág. 225. 
recoger los regalos que los españoles le harían llegar al rey George. Vallejo y Jonter exigieron, como paso previo a la entrega de los regalos, la devolución de los prisioneros, pero al no obtener respuesta aceptaron iniciar la negociación de cuáles serían los productos a traer al reino para ganarse la buena voluntad de sus habitantes. Esto sugiere la idea de que la diplomacia española se veía limitada en su desarrollo, por la imposición de las reglas de juego por parte de los miskitu.

Al no avanzar los tratos sobre la devolución de los prisioneros españoles, se entrevistaron Vallejo y Jonter con el rey George. Posteriormente, y ya en territorio del gobernador Briton, la comitiva española se enteró de la existencia de una "mestiza ynglesa" que era propietaria de "tres mugeres españolas." Estas mujeres habían estado "casadas" con indios, pero como estaban endeudados con la "ynglesa," ésta se las había quitado para cancelar la deuda. Cuando la comitiva española intentó recuperar a los prisioneros que tenía esta mujer en condición de esclavos (cuatro mujeres y cinco muchachos), todos españoles, tropezó con su negativa a entregarlos ya que implicaría para ella una gran pérdida económica. La mujer aducía que los indios a quienes le había quitado estos esclavos le debían "150 conchas de carey" y que no podía perder los "500 o 600 pesos que le producirían". Se logró acordar una compensación de 125 pesos y los prisioneros fueron embarcados en la corbeta San Pío, para retornarlos a sus lugares de origen. Por su parte, el gobernador Briton incumplía la promesa dada de entregar los únicos cuatro esclavos que asegurara tener en su poder, luego que "una niña de siete años huyera a la selva". Así pues, en este viaje sólo se obtuvo la devolución de nueve prisioneros españoles, cifra llamativa considerando lo asiduo de los ataques miskitu a los poblados españoles y la cantidad de prisioneros que se mencionaba en cada caso. ${ }^{43}$ Lo cierto es que los miskitu manifestaban una cierta resistencia a la devolución de los prisioneros españoles, a quienes consideraban "sus esclavos." Devolver a un prisionero se traducía a sus ojos como una pérdida económica, y lo usual era que se exigiese a cambio una retribución económica, que no siempre aceptaban pagar las autoridades españolas. Así fue como un jefe miskitu, el capitán Chacanía de la parcialidad del rey George, se presentó ante el comandante del establecimiento de Río Tinto para reclamar que se le compensase por la pérdida de su único esclavo, que luego de escaparse había buscado refugio en dicho establecimiento. Se trataba de un mulato libre de nombre Manuel

43 Ibídem, pág. 235. 
Josef Ayala, hecho prisionero durante uno de los ataques miskitu a los poblados del Pacífico y vendido al capitán Chacanía hacía ya doce años. El jefe miskitu exigía que se lo compensase por la pérdida sufrida ya que por Ayala había pagado " dos barquillas, una yegua, una escopeta y una manta", y no aceptaba las explicaciones que el comandante español le proporcionara acerca de que los prisioneros de guerra debían ser devueltos. ${ }^{44}$

Esta resistencia a la devolución de los prisioneros españoles no aparece marcada por un determinismo de género, si bien poco ha trascendido acerca de motivos extra económicos que pudiesen haber existido en el caso, por ejemplo, de las relaciones sexual-afectivas entabladas por los hombres miskitu con las mujeres capturadas. En el relato mencionado acerca de las cuatro mujeres españolas vendidas a los indios miskitu, y recuperadas porque éstos no habían saldado una deuda, es significativo que quien actuaba de intermediaria era una mujer mestiza. Queda aquí claro que la relación de subordinación no necesariamente puede ser siempre explicada en términos de desigualdades de género, sino que debe relacionarse con otros fenómenos tales como la pertenencia étnica y de clase, en un contexto social específico.

\section{El gobernador Briton, su cautiva y la diplomacia española.}

Durante 1782 se sucedieron los ataques de los indios y zambos miskitu a los poblados españoles. En un ataque realizado contra Juigalpa, en Nueva Segovia, provincia de Nicaragua, se llevaron los miskitu, entre otros prisioneros, a una niña de diez años - María Manuela Rodríguez Sanabria- y a seis muchachas mulatas: Brígida, Manuela Antonio, Ana Sanabria, Juana Bello, Ana Valdez y María Centeno. Estas cautivas fueron vendidas al gobernador Briton, siendo de su propiedad al iniciarse el período de presencia española en el reino. En ese entonces, María Manuela tenía quince años y, al parecer, el gobernador Briton se sentía atraído por la muchacha, por lo que había consentido en dejarse bautizar por Ana Sanabria. Esta "conversión" de Briton se extendió por voluntad suya a cuatro de sus esposas, Quili, Larinda, Miliori y Bisibel, a uno de sus hermanos de nombre Rabili, a su hijo Caluil y a su hija Mirimal. Durante su cautiverio María Manuela había dado su palabra de matrimonio al gobernador Briton. Quizás impulsado por estos motivos personales (su relación con María Manuela) o por la dinámica que tomaba la política del reino luego

44 AGS, Secretaría de Guerra, 6946, exp. 18... 
de la evacuación de la población británica, Briton aceptó una invitación para visitar la provincia de Nicaragua e impulsó al rey George a hacer lo mismo. Como muestra de sus buenas intenciones, aceptó devolver a sus cautivas de Juigalpa, a quienes envió de inmediato con una comitiva en la que se incluían algunos esclavos negros de regalo para el padre de María Manuela, y su hija Mirabel, entregada al cuidado de ésta como garantía de su palabra de matrimonio. Briton envió también a uno de sus hijos al virrey para que se le instruyera en la religión católica. ${ }^{45} \mathrm{La}$ actitud del gobernador miskitu no podía ser tomada más que con júbilo por parte de las autoridades españolas, pues podía significar el fin de más de un siglo de hostigamientos armados. Prueba de la recepción que tuvo el acercamiento iniciado por Briton fue que su hija Mirabel fue bautizada en la catedral de León el 6 de julio de 1787 por el obispo de la diócesis Juan Felix de Villega, siendo sus padrinos el propio gobernador de la provincia, Juan de Ayssa, y su esposa Agustina Lorraz.

Cuando a fines de 1788 se presentaron en Cartagena siete jefes principales zambos e indios para anunciar la próxima llegada del rey George y del gobernador Briton, fueron "tratados con mucha afabilidad en hospedaje, comida, vestuario y toda asistencia" por las autoridades españolas, ${ }^{46}$ y a la llegada de éstos se los alojó en casa del gobernador. La manifestación de Briton acerca de sus intenciones de repetir su bautizo, para asegurar validez al que otrora recibiera de la mulata Ana Sanabria, contó con el beneplácito del gobernador, quien lo organizó con toda la pompa que la personalidad del protagonista requería. La importancia de este suceso se reflejó en un artículo de La Gazeta, donde se mencionaba que:

"el mismo excelentísimo señor arzobispo virrey, que hizo el oficio de párroco, siendo padrino a nombre del rey nuestro señor el gobernador y comandante general de la plaza, yendo antes a conducir de su palacio al virrey al ayuntamiento de la ciudad, y todos los ministros, y su distinguido vecindario, formándose la tropa desde el palacio hasta la catedral, haciendo salva la fusilería al tránsito por las esquinas; en dicha catedral esperaba el prelado y cabildo eclesiástico con la clerecía y comunidades religiosas que asistieron al acto que se practicó con las ceremonias eclesiásticas y la mayor devoción, poniéndole los nombres de Carlos Antonio con el apellido de Castilla, y a el acto de echar el agua se hizo una salva con toda la fusilería y la artillería del baluarte más inmediato." ${ }^{47}$ pág. 116.

45 La Gazeta de Goatemala, del 6 de julio de 1788, citada en García Peláez: Memorias...,

46 Ibídem

47 Ibídem. 
Briton impresionó bien a las autoridades españolas, especialmente en su actitud devota. Pidió que se enviaran misioneros a su parcialidad y aseguró que haría cuanto estuviese a su alcance para lograr que los niños asistieran a recibir el sacramento y la instrucción religiosa, pero se mostró dudoso ante la actitud que adoptarían los adultos.

Por su parte, el rey George, era un observador externo y silencioso. En ocasiones se excusaba aduciendo problemas de salud para no presenciar el bautizo de algún miembro de su comitiva; en otras, se expresaba con dudas acerca de esta nueva religión que imponía al miskitu alejarse de sus esposas. ${ }^{48}$ Como la mayoría de los hombres principales del reino, George practicaba la poligamia teniendo más de diez mujeres. De él se ha dicho que "despojaba" de sus mujeres e hijas a sus súbditos, "apropiándolas quando y como se le acomoda." ${ }^{49} \mathrm{~A}$ estas afirmaciones puede oponerse la propia visión indígena, reflejada en los escritos de muchos de los cronistas, acerca del privilegio que implicaba para un padre entregar a su hija al cacique o al sacerdote para que éste la desvirgara. Esta costumbre, observada en América en tiempos precolombinos, resultaba chocante a ojos españoles. ${ }^{50}$ Ofrecer una mujer al rey George (el hombre más poderoso del grupo), o que éste la exigiese para sí, puede interpretarse como un honor del rey hacia los parientes de esa mujer e inclusive hacia ella misma. Lo cierto es que, al convertirse al catolicismo, Briton estaba dando un paso que lo separaba de la práctica usual de la poligamia, la cual simultáneamente George reivindicaría.

Una vez en Tubapi, Briton se detuvo poco, sólo lo necesario para delegar la gobernación en su hermano Robenly y regresó a León, desde donde envió un mensaje acompañado de su retrato al gobernador de Nicaragua, Juan de Ayssa, anunciándole sus intenciones de pedir a María Manuela el cumplimiento de su promesa de matrimonio. Aquí las fuentes se contradicen en ciertos detalles. Aparentemente, la respuesta de María Manuela fue clara y concisa, reiterando la promesa y su buena voluntad de llevar a cabo el matrimonio, haciendo saber a Briton que "de cuyo cumplimiento y palabra no debía dudar, sabiendo que era noble y española." ${ }^{11}$

Entran aquí en juego ciertos valores culturales y morales propios de aquel momento histórico que no pueden dejar de mencionarse. El modelo his-

48 Gámez: Historia..., pág. 153; García Peláez: Memorias..., pág. 118.

49 “Relación...", pág. 265.

50 Se observa, por ejemplo, que muchos padres ofrecían a sus hijas al cacique para que éste las desvirgara. Fernández de Oviedo, Gonzalo: Sumario de la natural historia de Indias, Madrid (1526) 1986, págs. 78-79.

51 Gámez: Historia..., pág. 153. 
pano de formación de las familias se basaba en el valor que se concedía a "la palabra de casamiento". Era éste un compromiso que ligaba a dos personas para la realización de una futura unión formal. De alguna manera "la palabra de matrimonio" constituía una situación similar a la de un matrimonio no consumado, pero podía revocarse de no haber existido contacto sexual. ${ }^{52}$ Había también otros atenuantes y la palabra de matrimonio podía romperse cuando, por ejemplo, se descubría que existían desigualdades étnicas o sociales que se considerasen muy grandes. Los matrimonios eran contratos acordados por los padres, que eran quienes decidían con quien debían casarse sus hijos; reconociendo a estos su derecho a aprobar o no dicha elección. Los factores de mayor peso al seleccionar pareja para los hijos solían ser la importancia social y la pertenencia étnica del pretendiente. En el caso de María Manuela y Briton, la palabra de matrimonio dada por ésta al gobernador durante su cautiverio sellaba una paz deseada por los españoles y volvía difusas o intranscendentes las diferencias étnicas. No obstante había ciertos problemas, como las relaciones polígamas de Briton, que debían solucionarse previamente para que el matrimonio contase con la aprobación de la Iglesia. Al entrevistarse María Manuela con el misionero Barrueta, enviado a Tubapi en misión religiosa a pedido del propio Briton, le manifestó su negativa, no a casarse, ya que estaría dispuesta a "sacrificarse", sino a retornar a aquella región, pidiendo que convenciera a Briton para que se trasladase a vivir a "tierra de cristianos." ${ }^{53}$ Barrueta, no obstante y por su cuenta, intentó discutir con Briton acerca de su decisión de contraer matrimonio con María Manuela $\mathrm{y}$, tratando de disuadirlo, le propuso que eligiera a aquella de sus esposas que fuese de su predilección para continuar casado con ella, separándose de las demás. Briton respondió que no quería "mujer mosquita sino española," y Barrueta comenzó a entrevistar a las esposas de Briton para averiguar cuál era la primera, y por lo tanto la "legítima", tratando de ordenar a las demás en orden temporal para que al concretarse el divorcio Briton pudiese indemnizarlas por orden de importancia. Esta tarea implicaba sus dificultades ya que:

"Hermenegilda Visibel, reputada por ser la primera...era cuarta en razón de tiempo, y primera o principal por jerarquía de nacimiento, que fue pedida a sus padres y entregada por estos sin contrato ni consentimiento suyo...además tenía otros cuatro esposos vivos y con todos ellos hijos." ${ }^{4}$

52. Lavrin, Asunción (ed.):Sexuality and Marriage in colonial Latin America. Lincoln/London, University of Nebraska Press, 1992.

53 García Peláez: Memorias..., pág. 119.

54 Ibídem. 
Cuando Barrueta intentó profundizar en las relaciones con las otras esposas surgió además que:

"unas eran cautivas, otras compradas y otras cogidas que no le agradaban, quisiesen ellas o no, no quedando a su arbitrio decir sí o no." ${ }_{55}$

El misionero resolvió finalmente divorciar a Briton de todas sus mujeres, declarándolo en libertad de volver a casarse. Una de las ex-esposas del gobernador, Magdalena Midioli, escribió a María Manuela en nombre de tres de ellas para transmitirle un recado de Hermenegilda Visibel, otra de las antiguas esposas:

"te suplica...que por amor de Dios te vengas, que mires que es preciso, porque quien ha de gobernar esta casa y quien se ha de doler de ella. Ya ves que Hermenegilda es mujer de edad, y después de Dios no tiene a quien dejarle sus hijos, sino es a vos, pues vos avís de ser la dueña de todo. Te prometemos quererte más que antes.”56

Es importante señalar el trato cercano con que Magdalena escribía a María Manuela. Su carta entablaba un diálogo de "mujer a mujer" entre las anteriores mujeres de Briton y aquella que era su prometida. No trascienden celos ni competencias, sino más bien una comunicación entre amigas que han convivido juntas, que saben que deben apoyarse y que se alegran al saber que una de ellas va a contraer matrimonio. No hay que olvidar que María Manuela fue raptada cuando sólo tenía diez años, e integrada a la casa del gobernador. Es muy posible que hubieran sido las esposas de éste quienes asumieron el cuidado de María Manuela, introduciéndola en las tareas domésticas que debía cumplir. Tampoco sería extraño que durante su larga permanencia en Tubapi, María Manuela no sólo aprendiese a expresarse con facilidad en la lengua indígena, sino que también su integración hubiera sido socio-cultural, es decir, que hubiese llegado a ocupar un lugar determinado dentro del sector femenino, no sólo del hogar del gobernador sino también del poblado. Se esperaba que María Manuela, luego de su matrimonio, asumiera el liderazgo de ese hogar, ocupándose especialmente del cuidado de la nueva generación. Su rol de madre no se vería circunscrito en forma exclusiva a los hijos biológicos que pudiera engendrar, sino también a los hijos de su marido.

Magdalena Midioli comunicaba también a María Manuela que el gobernador viajaría a León para concretar el matrimonio y que, desde que

55 Ibídem

56 Ibídem. 
éste regresara de su viaje anterior, no había mantenido contacto carnal con sus otras mujeres, diciendo que sólo las mantenía por los hijos. La carta de Briton a María Manuela anunciando su pronta llegada, confirmaba lo antedicho. El gobernador se refería a que Barrueta le había hecho saber que para ser cristiano debía dejar a todas sus mujeres y él aseguraba haberle contestado que:

"a todas las dejaba, desde luego, menos a una señora de que estaba prendado, que es U. Cuando venga no hallará en mi casa mujer ninguna. A U. la quiero por verdadera mujer legítima y esposa, para mientras dure la vida..."${ }^{57}$

En carta al obispo de León, Juan Felix de Villegas, diría Barrueta que Briton estaba tan ciego que, si no se casaba con doña María Manuela Rodríguez, no se sabía que podía llegar a hacer. ${ }^{58}$ Finalmente, y después de que varios religiosos se pronunciaron a favor de la libertad para casarse del gobernador, ya que sus anteriores matrimonios no podían considerarse tales de acuerdo a la doctrina cristiana, la unión entre el gobernador miskitu y la joven española se concretó en la catedral de León el día 21 de diciembre. Hay que señalar que Briton entregó a otros cinco prisioneros a su llegada a Granada, y que de las cartas de Barrueta transciende que en Tubapi había aún muchos otros.

El regreso de Briton y su esposa se produjo a fines de 1789, rodeado de los rumores de malestar que reinaban en la parcialidad y que llegan a sus oídos aun antes del arribo a Tubapi. Briton envió mensajeros a buscar a sus ex-mujeres, Hermenegilda Visibel, Magdalena Midiole y una tercera de la cual no sabemos su nombre. Estas le informaron que Alparis, su sobrino, se encontraba en posición de abierta rebeldía y que había llamado a junta para hacerse nombrar gobernador. Briton le envió el bastón, símbolo de su poder y de su deseo de verlo, pero Alparis no sólo no respondió sino que además no devolvió el bastón. Buscando aliados, logró Briton reunir en junta a sus jefes principales; juntas que se repitieron a diario durante un cierto período sin trascender el contenido de las discusiones. Poco a poco, Briton fue limitando la labor misionera de Barrueta ante la actitud de sus súbditos, especialmente los hombres que practicaban la poligamia y que veían en esta nueva religión un peligro para la continuidad del dominio doméstico tradicional. El rey George tampoco aprobaba la permanencia de 
los misioneros en tierras del reino, y esto había conducido a que ambos, George y Briton, estuviesen "encontrados." ${ }^{59}$ Un informe del establecimiento de Río Tinto, fechado el 25 de julio de 1789, se refería a la actitud disconforme del rey George y proponía:

"suavizarlo con regalos y unirlo a Briton, para que en corto tiempo se pudiese lograr...la cristiandad que abrazó Briton, y no me queda duda que se conformaría pues lo necesita." ${ }^{60}$

No era esto acertado, George contaba con mayor apoyo que Briton y, si bien había manifestado abiertamente que "él estaría con unos y con otros" ${ }^{61}$ refiriéndose a españoles e ingleses, lo haría obviamente en base a sus condiciones e intereses, y ya se había manifestado en contra de esta religión que impedía al hombre tener cuantas esposas quisiese.

Briton era consciente del peligro que corría su vida y así lo comunicó por escrito al gobernador Ayssa, a quien solicitó el envío de algunos hombres armados para su protección y la de su familia. En estas circunstancias, el gobernador volvió a rodearse de sus ex-mujeres, lo que le hizo ganarse el repudio del misionero Barrueta. No obstante, esta actitud más que signo de su desamor por María Manuela quizás no haya sido más que un intento por "rodearse de aliados", ya que estas mujeres eran quienes mantenían a Briton informado del malestar social. Cuando el peligro era inminente, Briton decidió que era hora de que María Manuela, que estaba embarazada, regresara con su familia. Su decisión resultó ser acertada, ya que poco después Briton moría asesinado, según las fuentes consultadas, a manos de su sobrino Alparis con ayuda del rey George. Alparis no sólo se convirtió en el nuevo gobernador, sino que además, ayudado por su hermano Solera, se dirigió a Bluefields para atacar el establecimiento de Roberto Hodgson, a quien perdonó la vida sólo por las súplicas de su mujer, Isabel Pytt. Cuando posteriormente se le preguntó a Alparis qué motivos le habían llevado a atacar a Hodgson y a saquear su establecimiento, respondió que "había sido mui malo con los indios, y que no lo querían, pero que a su esposa sí la estimaban." ${ }^{62}$ Los Hodgson abandonaron todos sus bienes y se dirigieron a León a dar cuenta de lo sucedido. La revuelta de Alparis y la

59 ASG, Secretaría de Guerra, 6949. Exp. 20. 1791.

60 Ibídem.

61 Conversación entre Briton y George en Cartagena durante el bautizo del primero, transcripta en Gámez: Historia..., pág. 153, y García Peláez: Memorias...

62 AGS, Secretaría de Guerra, 6950. Exp. 6. 1792. 
pérdida de estos dos aliados fuertes (Briton y Hodgson) dificultaría la permanencia de los españoles en la región.

Dada la importancia de lo sucedido, las autoridades españolas enviaron una comisión para investigar los hechos y "explorar las intenciones de los jefes indios de la Costa de Mosquitos". ${ }^{63}$ Un subteniente español, Juan Sivelly, acompañado por un médico inglés, Francisco Meani, recorrieron los poblados de los indios y zambos, reflejando en un diario de viaje las entrevistas que sostuvieron. Este material ofrece una nueva visión sobre la muerte de Briton, así como también profundiza en la personalidad del rey George, de Alparis y permite dar continuidad al destino de algunas de las ex-esposas de Briton.

Se informa que varios indios de la parcialidad de Briton habían pedido ayuda al rey George, quejándose del "maltrato" que recibían de aquél, entendiéndose por tal su empeño en imponer la monogamia en los territorios de su dominio. La reacción contra Briton había ido en aumento hasta que comenzó a planearse su asesinato. Se habían producido dos intentos fallidos en Haulver, detrás de los cuáles se descubriría el apoyo de Roberto Hodgson a Alparis mediante el suministro de municiones. Los partidarios del rey George aseguraban que éste había tratado de mediar, pidiendo que los indios miskitu intentasen resolver esta cuestión dentro de su parcialidad. Sin embargo, el papel del rey no queda totalmente claro. Los distintos testigos informaron que, cuando Briton pasó por Sandy Bay en la piragua en que alejaba a su familia con el fin de ponerla a salvo, fue interceptado por el rey George, quien no le dejó continuar el viaje hasta que respondiera a las acusaciones que había en su contra. Briton fue así detenido por George, pero:

"después de algunos días el gobernador hizo fuga, pero...no siendo práctico en aquellos caminos fue aprendido y recombenido por que hacia fuga sino tenia delito, no quiso contestar diciendo solo que sabia que había de morir, y así que lo despachasen luego, lo que verificaron a los dos días." ${ }^{64}$

Esta primera versión se amplía con otra, según la cual Briton debió presentarse a una junta de principales, quienes

"resolvieron devia morir, comunicose esta resolución a George que no se había presentado en junta y que contra su ánimo había consentido por no dar un exemplo, y que este consentimiento lo dio temiéndose una rebuelta de los suios contra el." ${ }^{65}$

63 Ibídem.

64 Ibídem.

65 Ibídem. 
Algunos testigos informaron que el gobernador Briton, luego de ser sentenciado en esta junta, fue ahorcado por los capitanes miskitu Wilson Powel, Pedro el Cristiano y "otros de la plebe," siendo enterrado allí mismo. ${ }^{66}$

La comisión española increpaba a los testigos, preguntando si no creían que actuando de esta manera ofenderían al gobierno español; una y otra vez recibían la misma respuesta: que el gobernador había sido cruel pretendiendo "que los hombres tuviesen una sola mujer." ${ }^{67}$ Es así como la actitud consecuente del gobernador Briton al declarar su amor a María Manuela y afirmar que sería la "única mujer de su vida" lo había llevado a tratar de que sus súbditos siguiesen este ejemplo, originando la rebelión que acabaría con sus días.

Poco se sabe de María Manuela con posterioridad a este suceso, sólo que nunca volvió a casarse y que tuvo un hijo al que llamó con el nombre cristiano de Briton, Carlos Antonio de Castilla.$^{68}$ Las mujeres anteriores del gobernador, por su parte, enteradas de la llegada de la comisión española para investigar su muerte se presentaron a declarar y pidieron apoyo, ya que decían estar perseguidas por Alparis y por otros indios principales, quienes querían vengar en ellas la preferencia monógama de Briton. Meani y Sivelly registraron en su diario:

"Aquí llego la india Francisca, una de las antiguas mugeres que el difunto don Carlos de Castilla tenia antes de imponerse los sagrados ritos de nuestra religión, y presentándonos dos hijos del referido nos suplicó la auxiliásemos y amparásemos para pasar a un establecimiento español, por razón de que entre los indios recibían maltrato, y amenazaban de hacer esclavos a los citados hijos cristianos en lugar de los prisioneros que Briton había quitado a sus gentes, sin satisfacerles lo que havian pagado por ellos.”69

Hermenegilda Visibel y su hija María Micaela se encontraban en la misma situación. Según la anotación del diario:

"A las dos de la tarde llegamos a Bragmans, en donde hallamos a la citada Esmeregilda con María Micaela, hija maior del difunto Don Carlos Antonio de Castilla, las que nos hicieron la misma súplica de la Francisca, añadiendo la Esmeregilda, que temía que alguno de los jefes con violencias le quitara su hija para hacerla su muger, lo que sentía mas que todo otro maltrato por ser ambas cristianas y no querían que la casasen con infiel" 70

66 Ibídem.

67 Ibídem.

68 Gámez: Historia..., pág. 161.

69 Ibídem.

70 Ibídem. 
Detrás de estas persecuciones estaba el nuevo gobernador Alparis, quien tenía su residencia en Arenas Blancas, población de veinte y seis casas. Poco antes de la muerte de Briton, Alparis fue visitado por un español quien lo describía como "absoluto y despótico", señalando además que tenía tres ingleses en el poblado que profesaban odio a los españoles "administrando a los indios iguales sugestiones." El capitán español transmitiría la siguiente imagen de Alparis, entonces almirante, a sus superiores:

"le hallé decentemente vestido, con vn sombrero de plumas, botas y espada, ostentando su bastón. Vi un personage de agradable, aunque grave presensia, que en el modo de proponer sus razones manifestaba una índole sencilla y un animo despejado."’11

Las actitudes abusivas de Alparis desde que había ocupado el puesto de su tío, le comenzaron a crear enemistades, aun entre los suyos. Se sabe que luego del ataque y saqueo al establecimiento de Hodgson, el rey George envió a algunos zambos a guardar las cosechas y los animales del inglés, para que estuviesen a disposición de su esposa, Isabel Pytt, cuando ésta los reclamase. Sus enviados fueron interceptados por Alparis y su hermano Solera, quienes se llevaron todo. Mientras que Solera reconocía el hecho, Alparis no sólo lo negaba sino que decía desconocer el paradero de estos bienes, al ser interrogado por Sivelly y Meani al respecto. Igual sucedía con las pertenencias personales de Briton y María Manuela, que se intentaron recuperar para devolverlas a ésta última.

Las denuncias contra Alparis eran también por abusos con las mujeres. Una mestiza de habla inglesa, María Trenk, que habitaba en Laguna de Perlas, suplicaba a Sivelly y Meani que intercedieran para que Alparis "no la incomodase como acostumbraba" ya que éste amenazaba con "quitarle una prima suia y obligarle a servirle como esclava." ${ }^{2}$ Por otra parte, una india se presentó a denunciar que habiendo Alparis realizado ciertas compras en un barco inglés, y quedando con el saldo desfavorable, había acabado por saldar su deuda entregando al capitán a su hija, que era una "zamba libre de 16 años". ${ }^{73}$

Es interesante la actitud crítica y de manifiesto rechazo de estas mujeres ante actitudes que atropellaban su libre albedrío en cuestiones relativas al sexo. Así como las ex-mujeres de Briton denunciaban actitudes de autoritarismo de los hombres, que coartaría la libertad de las hijas de éste para

71 "Relación del reconocimiento...", pág 270.

72 AGS, Secretaría de Guerra, 6950. Exp. 6. 1792.

73 Ibídem. 
elegir pareja, estas otras dos mujeres se oponían a los avances sexuales no deseados, forma en que se explicitaba el dominio despótico masculino. Por los pocos datos que poseemos no es posible generalizar; sin embargo, podría indicarse una tendencia hacia la no aceptación de su subordinación por parte de las mujeres, independientemente de su pertenencia étnica. Existía, sin embargo, un control indiscutible de la sexualidad femenina ejercida por los hombres miskitu sobre las mujeres de los demás grupos étnicos, resultado de su supremacía militar. Este control masculino se extendía a las mujeres de su propio grupo en casos más limitados y relacionados siempre a una situación coyuntural. Lo cierto es que, al parecer, las mujeres miskitu poseían mayor libertad de decisión sobre sus relaciones sexual-afectivas que las demás mujeres de la región. Como ejemplo puede recordarse a la primera esposa de Briton, de quien el misionero Barrueta dijera que además de éste tenía otros cuatro "esposos", todos vivos y con todos ellos hijos.

Respecto a la situación del reino después de la muerte de Briton, puede decirse que Alparis sufrió las consecuencias de haberse manifestado en contra del rey George. Alparis, no conforme con ocupar el lugar de Briton había comenzado a reivindicar el cargo de rey, puesto que él era "un verdadero yndio." ${ }^{74}$ Estas amenazas, que no sólo cuestionaban la autoridad del rey sino la supremacía de los zambos sobre los indios, no cayeron en oídos sordos y el rey George comenzó a expresarse en favor de limitar la autoridad de Alparis. Al acompañar George a Meani y Sivelly al establecimiento de Río Tinto, solicitó una entrevista a puerta cerrada con el comandante español de dicho establecimiento para manifestarle que estaba dispuesto a castigar a Alparis, ya que éste acabaría por "ser la causa por su mal proceder de la desgracia de su nación..” ${ }^{\prime 5}$ Meani y Sivelly anotaron en su diario que:

"la providencia dicta qual seria la respuesta del comandante y nuestra, se le dijo que haria mui mal de tomar satisfacción por si mismo de unas cosas que solo dependen del Exmo Sr. Presidente del Reyno, replico Jorge que consideraba que el Exmo estaba muy distante de Río Grande."’

Obviamente, la decisión del rey George estaba ya tomada aquel domingo 4 de diciembre de 1791 y seguramente contó con algún beneplácito por parte de la autoridad española, ya que Meany y Sivelly registraron que:

74 Ibídem.

75 Ibídem.

76 Ibídem. 
"viendo que era infructuosa qualquier proposición para persuadirle de lo contrario se concluio la conversación, y Jorge volvió a la sala del concurso con las mas grandes señales de satisfacción y confianza, de modo que si no nos equivocamos, es la sola vez que Jorge casi sin acompañamiento, que mandó retirarse, quedó tan confiado tarde en el establecimiento." 77

Poco después, Alparis, tres de sus mujeres y doce indios importantes de su parcialidad serían asesinados por órdenes del rey George, quedando éste desde esos momentos como autoridad máxima del reino, con domino tanto sobre zambos como sobre indios miskitu. A partir de entonces se unificó el reino, desapareciendo en forma paulatina muchas de las diferencias entre zambos e indios.

Si bien en un comienzo la historia de amor entre María Manuela y Briton permitió vislumbrar la paz entre los españoles y los miskitu, el asesinato de éste significaría el fin de toda esperanza en este sentido, así como también de la intervención española en la Costa de Mosquitos. Con este evento desapareció la presencia misionera en el área por más de sesenta años, siendo reanudada por los moravos recién en 1849 en Bluefields y en 1883 en las zonas de predominio miskitu. Otra consecuencia del asesinato de Briton fue la supervivencia de las costumbres tradicionales y del dominio de las prácticas de poligamia, que perdurarían pese a la conversión religiosa.

77 Ibídem. 